\title{
Ventricular Tachycardia in Children
}

\author{
ALBERT P. ROCCHINI, MD* \\ PATRICK O. CHUN, MD ${ }^{\dagger}$ \\ MACDONALD DICK, MD ${ }^{\dagger}$
}

Ann Arbor, Michigan
From the Section of Pediatric Cardiology, Department of Pediatrics and Communicable Diseases, University of Michigan Medical Center, C. S. Mott Children's Hospital, Ann Arbor, Michigan* and the Department of Cardiology, Walter Reed Army Medical Center, Washington, D.C. ${ }^{\dagger}$ Manuscript received Octobeir 13, 1980; revised manuscript received December 3, 1980, accepted December 18, 1980.

Address for reprints: Albert P. Rocchini, MD, Pediatric Cardiology, C. S. Mott Children's Hospital, Ann Arbor, Michigan 48109.
Thirty-eight patients aged 1 to 20 years (mean 11.2) were evaluated because of recurrent ventricular tachycardia. The follow-up period ranged from 0.5 to 12 years (mean 6 ). The patients were separated into two groups according to the presence or absence of known structural heart disease. Seventeen of the 21 patients with known heart disease were symptomatic (cardiac arrest in 5, syncope in 5, dizziness in 7) compared with only 6 of the 17 patients without heart disease (syncope in 3 and dizziness in 3 ) ( $p<0.01$ ). All symptomatic patients had ventricular tachycardia with rates of more than 150 beats/min, whereas all but one of the asymptomatic patients had rates of less than 150 beats/min ( $p$ $<0.01)$. Graded treadmill exercise testing was performed in 21 of the 38 patients. Exercise increased the degree of ventricular arrhythmia in 8 of the 11 symptomatic patients but decreased or abolished the arrhythmia in 9 of the 10 asymptomatic patients $(p<0.01)$.

Antiarrhythmic therapy was used in 28 of the $\mathbf{3 8}$ patients. Effectiveness of therapy was assessed with both 24 hour Holter monitoring and graded treadmill exercise testing. Therapy effectively abolished ventricular tachycardia and greatly decreased the number of premature ventricular complexes in the symptomatic patients but was less effective in the asymptomatic patients. Thus, this study suggests that the presence of underlying heart disease, the rate of ventricular tachycardia and the results of graded treadmill exercise tests are important in predicting the prognosis of children with ventrlcular tachycardia.

Ventricular tachycardia, unrelated to metabolic disorders, drugs or anesthesia or occurring during procedures such as surgery and cardiac catheterization, is rare in infants and children. ${ }^{1-9}$ Recent advances in ambulatory electrocardiographic recordings and invasive electrophysiologic studies have increased our knowledge about ventricular arrhythmias in children, but little is known about the long-term course of these patients. ${ }^{1}$ In this report we review our experiences with ventricular tachycardia and assess the factors that are important in determining the prognosis of children with this arrhythmia.

\section{Methods}

Patients: The diagnostic files of the Departments of Pediatric Cardiology and Cardiovascular Surgery at the C. S. Mott Children's Hospital, University of Michigan and the Department of Cardiology at the Walter Reed Army Medical Center were searched and the records of 38 children who had ventricular tachycardia were obtained and reviewed. In each patient, a complete history, physical examination, serial electrocardiogram, 24 hour Holter electrocardiograms, $M$ mode echocardiograms and chest X-ray films were available. Laboratory tests in all 38 patients also included a complete blood count, urinalysis and determination of serum electrolytes including sodium, potassium, calcium and phosphorus, blood gases and serum thyroxine. Graded treadmill exercise testing using the Bruce protocol ${ }^{10}$ was performed in 21 patients and cardiac catheterization in 24. The diagnosis of ventricular tachycardia was made using standard scaler electrocardiographic criteria of a succession of three or more ventricular extrasystoles with atrioventricular dissociation and fusion and capture QRS complexes. ${ }^{1}$ 
Electrophysiologic studies: Seven patients underwent electrophysiologic study using one or two tripolar, quadripolar or hexapolar electrode catheters introduced into one femoral vein. All patients were premedicated with morphine, 0.1 $\mathrm{mg} / \mathrm{kg}$ body weight, and benadryl, $1 \mathrm{mg} / \mathrm{kg}$. Intracavitary tracings along with scalar leads I, II, and III were recorded on a multichannel oscilloscope recorder (Electronics for Medicine VR 12) at a paper speed of $100 \mathrm{~mm} / \mathrm{s}$, using a filter setting of 40 to 500 hertz for intracavitary electrograms. The right atrium in all seven patients and the apex of the right ventricle in four were stimulated using a programmable stimulator (Medtronic 5325). In all seven patients premature atrial stimulation during sinus rhythm was performed. The entire cardiac cycle was scanned to the point of atrial refractoriness. Atrial pacing at rates of 120,150 and 180 beats $/ \mathrm{min}$ for 30 seconds was also performed in all seven patients. Finally, in four patients, premature ventricular stimulation during right ventricular pacing was performed. The entire cardiac cycle was scanned to the point of ventricular refractoriness. Procainamide or phenytoin was then given intravenously and ventricular stimulation was repeated.

\section{Results}

Clinical features (Table I): Cardiovascular abnormalities were present in 21 of the 38 patients. These included mitral valve prolapse in five patients, repaired

TABLE I

Clinical Data in 38 Patients with Ventricular Tachycardla

\begin{tabular}{|c|c|c|c|c|c|c|c|}
\hline Case & $\begin{array}{c}\text { Age (yr) } \\
\text { at Diagnosis } \\
\text { of VT }\end{array}$ & Sex & $\begin{array}{c}\text { Follow-Up } \\
\text { (yr) }\end{array}$ & $\begin{array}{c}\text { Cardiac } \\
\text { Diagnosis }\end{array}$ & $\begin{array}{l}\text { Rate of VT } \\
\text { (beats } / \mathrm{min} \text { ) }\end{array}$ & Symptoms & Therapy \\
\hline \multicolumn{8}{|c|}{ Patients With Underlying Heart Disease } \\
\hline $\begin{array}{l}1 \\
2 \\
3 \\
4 \\
5 \\
6\end{array}$ & $\begin{array}{r}8 \\
6 \\
17 \\
11 \\
13 \\
1\end{array}$ & $\begin{array}{l}F \\
M \\
M \\
F \\
M \\
M\end{array}$ & $\begin{array}{l}2 \\
8 \\
3 \\
7 \\
6 \\
2\end{array}$ & $\begin{array}{l}\text { MVP } \\
\text { MVP } \\
\text { MVP } \\
\text { MVP } \\
\text { MVP } \\
\text { Myocarditis }\end{array}$ & $\begin{array}{l}200-250 \\
180-200 \\
200-240 \\
170-220 \\
180-200 \\
250-300\end{array}$ & $\begin{array}{l}\text { Arrest } X 2 \\
\text { Syncope } \\
\text { Arrest } \\
\text { Syncope } \\
\text { Dizziness } \\
\text { Arrest } \\
\text { (died from CHF) }\end{array}$ & $\begin{array}{l}\text { Prop, quin } \\
\text { Prop } \\
\text { Prop, quin } \\
\text { Prop } \\
\text { Prop } \\
\text { Quin, dig }\end{array}$ \\
\hline $\begin{array}{l}7 \\
8 \\
9\end{array}$ & $\begin{array}{r}5 \\
12 \\
7\end{array}$ & $\begin{array}{l}F \\
F \\
M\end{array}$ & $\begin{array}{r}3 \\
10 \\
6\end{array}$ & $\begin{array}{l}\text { Myocarditis } \\
\text { Myocarditis } \\
\text { Prolonged } \\
\text { Q-T }\end{array}$ & $\begin{array}{l}130 \\
130-150 \\
200-240\end{array}$ & $\begin{array}{l}\text { None } \\
\text { None } \\
\text { Arrest }\end{array}$ & $\begin{array}{l}\text { Phen, quin, dig } \\
\text { None } \\
\text { Prop, phen }\end{array}$ \\
\hline 10 & 1.5 & $\mathbf{F}$ & 2 & $\begin{array}{l}\text { Prolonged } \\
\text { Q-T }\end{array}$ & 250 & Arrest & Prop, phen \\
\hline 11 & 6 & M & 6 & $\begin{array}{l}\text { Prolonged } \\
\mathrm{Q}-\mathrm{T}\end{array}$ & 230 & Syncope & Prop \\
\hline $\begin{array}{l}12 \\
13 \\
14 \\
15 \\
16 \\
17\end{array}$ & $\begin{array}{r}18 \\
16 \\
16 \\
19 \\
6 \\
9\end{array}$ & $\begin{array}{l}M \\
M \\
M \\
F \\
M \\
M\end{array}$ & $\begin{array}{l}4 \\
1 \\
3 \\
2 \\
2 \\
0.4\end{array}$ & $\begin{array}{l}\text { Postop ToF } \\
\text { Postop ToF } \\
\text { Postop ToF } \\
\text { Postop ToF } \\
\text { sub AS } \\
\text { AS }\end{array}$ & $\begin{array}{l}180-200 \\
170 \\
180 \\
160-190 \\
140 \\
220-300\end{array}$ & $\begin{array}{l}\text { Syncope } \\
\text { Palp, dizziness } \\
\text { Dizziness, palp } \\
\text { Dizziness, palp } \\
\text { None } \\
\text { Angina, dizziness } \\
\text { (died at AVR) }\end{array}$ & $\begin{array}{l}\text { Dig, quin, phen } \\
\text { Phen } \\
\text { Phen } \\
\text { Phen } \\
\text { None } \\
\text { Quin, dig }\end{array}$ \\
\hline 18 & 17 & M & 8 & Al & $250-290$ & $\begin{array}{l}\text { Angina, palp, } \\
\text { dizziness }\end{array}$ & Proc \\
\hline 19 & 15 & $\mathbf{M}$ & 3 & $\begin{array}{l}\text { s/p MVR, } \\
\text { VSD }\end{array}$ & 225 & dizziness, palp & Quin, dig \\
\hline 20 & 3 & M & 1 & $\begin{array}{l}\text { Mitral } \\
\text { atresia, } \\
\text { single } \mathrm{V} \text {, }\end{array}$ & 250 & $\begin{array}{l}\text { Cyanosis, } \\
\text { syncope } \\
\text { (dled from CHF) }\end{array}$ & Dig, quin \\
\hline 21 & 0.2 & $\mathbf{M}$ & 0.5 & Postop TAPVR & 150 & None & Dig, prop \\
\hline \multicolumn{8}{|c|}{ Patients With No Heart Disease } \\
\hline $\begin{array}{l}22 \\
23 \\
24 \\
25 \\
26 \\
27 \\
28 \\
29 \\
30 \\
31 \\
32 \\
33 \\
34 \\
35 \\
36 \\
37 \\
38\end{array}$ & $\begin{array}{l}2 \text { day } \\
3 \\
9 \\
13 \\
13 \\
15 \\
14 \\
15 \\
20 \\
20 \\
16 \\
14 \\
9 \\
16 \\
10 \\
14 \text { days } \\
8\end{array}$ & $\begin{array}{l}\mathbf{M} \\
\mathbf{M} \\
\mathbf{F} \\
\mathbf{M} \\
\mathbf{F} \\
\mathbf{F} \\
\mathbf{M} \\
\mathbf{M} \\
\mathbf{F} \\
\mathbf{F} \\
\mathbf{M} \\
\mathbf{F} \\
\mathbf{F} \\
\mathbf{M} \\
\mathbf{F} \\
\mathbf{M} \\
\mathbf{M}\end{array}$ & $\begin{array}{c}7 \\
3 \\
3 \\
3 \\
3 \\
5 \\
7 \\
7 \\
2 \\
9 \\
12 \\
4 \\
5 \\
3 \\
7 \\
0.5 \\
4\end{array}$ & $\begin{array}{l}\text { None } \\
\text { None } \\
\text { None } \\
\text { None } \\
\text { None } \\
\text { None } \\
\text { None } \\
\text { None } \\
\text { None } \\
\text { None } \\
\text { None } \\
\text { None } \\
\text { None } \\
\text { None } \\
\text { None } \\
\text { None } \\
\text { None }\end{array}$ & $\begin{array}{l}145-120 \\
140-150 \\
100-140 \\
100-120 \\
140 \\
135-145 \\
160-180 \\
120-140 \\
150-190 \\
180-260 \\
160-280 \\
120 \\
140 \\
170 \\
220 \\
150-170 \\
120\end{array}$ & $\begin{array}{l}\text { None } \\
\text { None } \\
\text { None } \\
\text { None } \\
\text { None } \\
\text { None } \\
\text { Syncope } \\
\text { None } \\
\text { Dizziness, palp } \\
\text { Syncope } \\
\text { Syncope } \\
\text { None } \\
\text { None } \\
\text { Dizziness } \\
\text { Dizziness } \\
\text { None } \\
\text { None }\end{array}$ & $\begin{array}{l}\text { None } \\
\text { None } \\
\text { Prop, quin } \\
\text { None } \\
\text { None } \\
\text { Prop } \\
\text { Prop } \\
\text { None } \\
\text { Prop, quin } \\
\text { Prop } \\
\text { Prop, quin } \\
\text { None } \\
\text { None } \\
\text { Prop, quin } \\
\text { Prop } \\
\text { Prop } \\
\text { None }\end{array}$ \\
\hline
\end{tabular}

Al = aortic insufficiency; $A S=$ aortic stenosis; $A V R=$ aortic valve replacement; CHF = congestive heart failure; Dig = digoxin; $M$ VP = mitra valve prolapse; MVR = mitral valve replacement; Palp = palpitations; Phen = phenytoin; Postop = postoperative; Proc = procainamide; PS = pulmonary stenosis; Quin = quinidine; s/p = status post; TAPVR = total anomalous pulmonary venous return; ToF = tetralogy of Fallot; $V=$ ventricle; VSD = ventricular septal defect; VT = ventricular tachycardia. 
TABLE \|

Symptoms in Patients With Ventricular Tachycardia

\begin{tabular}{lcc}
\multicolumn{1}{c}{ Heart Disease } & No Heart Disease \\
\hline Symptoms & 0 & 0 \\
Death & 5 & 0 \\
Cardiac arrest & 5 & 3 \\
Syncope & 7 & 3 \\
$\begin{array}{l}\text { Dizziness and/or } \\
\quad \text { lightheadedness }\end{array}$ & & 6 of 16 \\
$\begin{array}{l}\text { Total patients } \\
\text { with symptoms }\end{array}$ & 17 of 21 & $(p<0.01)$ \\
\hline
\end{tabular}

tetralogy of Fallot in four, myocarditis in three, prolonged $Q-T$ syndrome in three and other congenital heart lesions in six. Seventeen patients had no known heart disease. There were no significant differences between the patients with and without heart disease with regard to age at diagnosis of ventricular tachycardia ( 0.2 to 19 years [mean \pm standard error of the mean $9.8 \pm 2.5$ ] versus 2 days to 16 years [mean $11.5 \pm$ 3.2 years $])$; and duration of follow-up (0.4 to 10 years [mean $3.9 \pm 2.7$ ] versus 0.5 to 12 years [mean $4.9 \pm 2.6$ ]). There were three deaths in the patients with heart disease, all secondary to the underlying heart disease (severe congestive heart failure in Patients 6 and 20 and aortic stenosis [during aortic valve replacement] in Patient 17); there were no deaths in the patients without heart disease.

Cardiac catheterization findings: Cardiac catheterization was performed in 24 of the 38 patients ( 19 of the 21 patients with and 5 of the 17 patients without underlying heart disease). Left ventricular asynergy was observed in all five patients with mitral valve prolapse. Left ventricular dysfunction, as documented by an ejection fraction of less than 50 percent, was present in all three patients with myocarditis. No abnormalities of left ventricular function or contraction pattern were noted in the five patients without heart disease. Selective right and left coronary angiography ruled out the presence of abnormal coronary circulation in 10 of the patients.

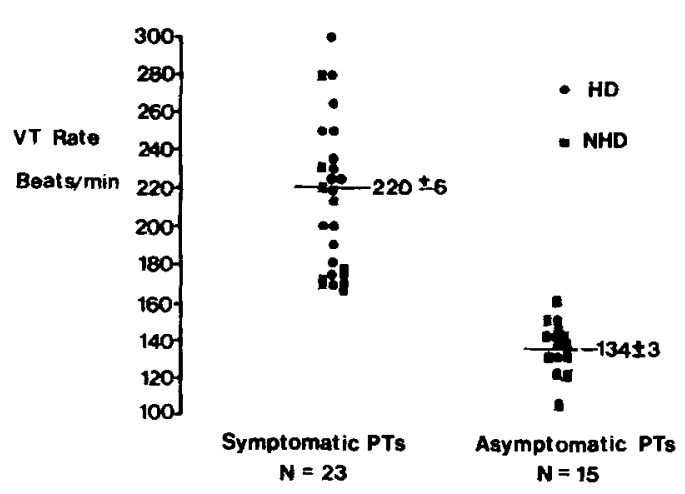

FIGURE 1. Graph demonstrating the relation between symptoms and the rate of ventricular tachycardia (VT) at rest. The closed circles represent the patients (Pts) with heart disease (HD); the squares represent the patients without known heart disease (NHD); the horizontal rules indicate mean values \pm standard error of the mean.
Symptoms due to ventricular tachycardia (Table II): Symptoms directly referable to the ventricular tachycardia were observed in 17 of the 21 children with and in 6 of the 17 children without heart disease ( $p$ $<0.01$, chi-square $=6.7$ ). The patients with underlying heart disease not only had more symptoms, but also their symptoms were more severe. Cardiac arrest requiring cardiopulmonary resuscitation and cardioversion occurred in 5 of the 17 symptomatic children with heart disease and in none of the children without heart disease. Three of the patients without heart disease (Patients 28, 31 and 32) had been followed up for 5, 6 and 8 years, respectively, with asymptomatic ventricular tachycardia before a syncopal episode developed.

Like the presence of heart disease, the rate of ventricular tachycardia appears to be related to symptoms (Fig. 1). Symptomatic patients had a significantly faster rate of ventricular tachycardia than that of the asymptomatic patients $(220 \pm 28$ versus $134 \pm 12$ beats $/ \mathrm{min})$ ( $\mathrm{p}<0.01$ ). All symptomatic patients, whether or not they had underlying heart disease, had rates of ventricular tachycardia greater than 150 beats/min, whereas only one asymptomatic patient (Patient 37, a 14 day old infant) had such a rate (Fig. 2).
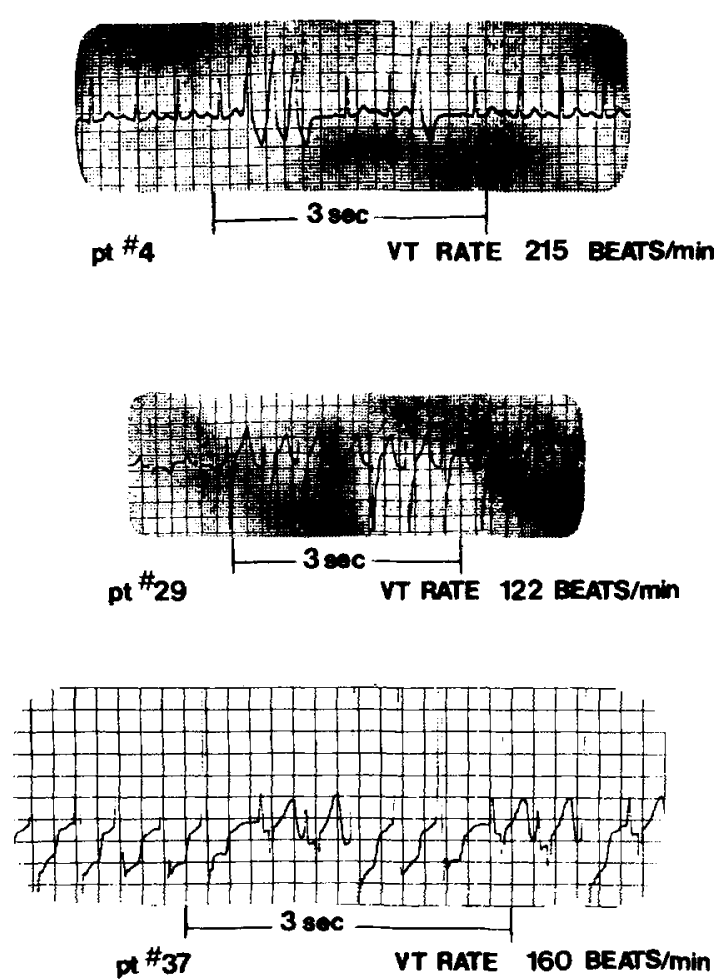

FIGURE 2. Representative electrocardiographic strips obtained from three patients ( $p t)$ with ventricular tachycardia. Patient 4 has predominantly normal sinus rhythm with a burst of ventricular tachycardia (VT) at a heart rate of 215 beats/min. Patient 29 has a Holter monitor strip that demonstrates ventricular tachycardia at $122 / \mathrm{min}$. This patient has no known heart disease as documented by cardiac catheterization studies including ventricular and coronary angiography as well as normal $\mathrm{M}$ mode and two dimensional echocardiograms. Patient 37 is the 14 day old infant with ventricular tachycardia at a rate of $160 / \mathrm{min}$. This strip is from a Holter monitor recording with twice normal standardization. 
TABLE III

Symptoms Versus Results of Exercise Testing in 21 Chlidren With Ventricular Tachycardia

\begin{tabular}{|c|c|c|c|}
\hline & $\begin{array}{l}\text { Symptomatic } \\
\qquad(\mathrm{n}=11)\end{array}$ & $p$ & $\begin{array}{l}\text { Asymptomatic } \\
(n=10)\end{array}$ \\
\hline No change in PVCs & 3 & & 1 \\
\hline $\begin{array}{l}\text { Increase in PVCs } \\
\text { Couplets } \\
\text { VT }\end{array}$ & 8 & $<0.01$ & 0 \\
\hline $\begin{array}{l}\text { Decreased or abolished } \\
\text { PVCs }\end{array}$ & 0 & $<0.01$ & 9 \\
\hline
\end{tabular}

PVCs $=$ premature ventricular complexes.

The rate of the ventricular tachycardia varied in the same child with time; however, no symptomatic patient had a documented ventricular tachycardia rate of less than 150 beats/min, and only three of the asymptomatic patients (Patients 8, 21 and 37) had a rate greater than or equal to 150 beats/min.

Exercise testing: Graded treadmill exercise testing was performed in 21 of the 38 children with ventricular tachycardia (Table III). Exercise testing increased the degree of ventricular arrhythmia in 8 of 11 symptomatic patients. Ventricular tachycardia was precipitated by exercise in six of these children (Fig. 3 and 4). Five children experienced symptoms with their exerciseinduced ventricular tachycardia (dizziness in Patients $3,4,28$ and 31$]$ and sustained ventricular tachycardia requiring cardioversion in Patient 18 (Fig. 4). Patients 32 and 36 exhibited ventricular couplets during treadmill exercise performed 0.5 to 2 years before the development of symptomatic ventricular tachycardia. In

FIGURE 3. Patient 31. Exercise stress test in a patient with no known heart disease. Ventricular tachycardia (VT) was provoked at 7 . minutes of exercise and the rate of ventricular tachycardia increased from 185 to 250 beats/min at 8 minutes of exercise.
REST
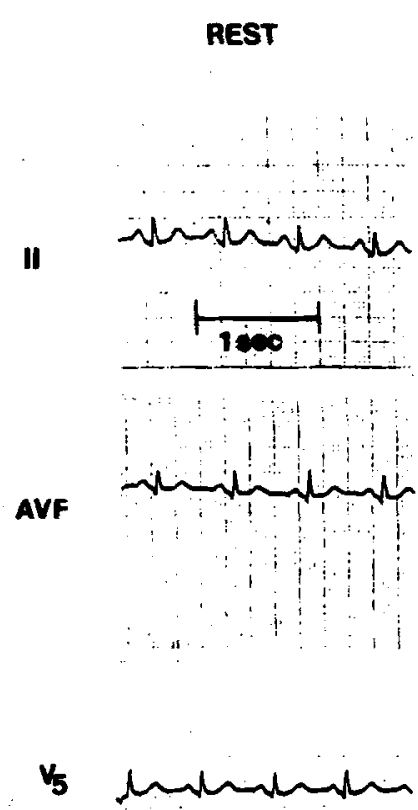

contrast to results in the symptomatic patients, treadmill exercise testing decreased (5 patients) or abolished (4 patients) ventricular arrhythmia in 9 of 10 asymptomatic patients. Four of the asymptomatic patients (Patients 24 to 26 and 34) had short bursts of ventricular tachycardia at rest that were suppressed by exercise.

Electrophysiologic data: Seven patients (Patients $1,4,7$ and 12 to 15 ) underwent an electrophysiologic study. Patient 7 had frequent spontaneous bursts of ventricular tachycardia that could be suppressed by atrial or ventricular pacing at a rate greater than 135 beats/min. Programmed stimulation of the atrium failed to initiate ventricular tachycardia in all seven patients.

Single or double spontaneous ventricular responses occurred after premature ventricular stimulation during ventricular pacing in Cases 12 to 15 . In three of these patients intravenous administration of either procainamide (Patients 13 and 15) or phenytoin (Patient 14) abolished the repetitive ventricular response.

Antiarrhythmic therapy: This therapy was initiated in 28 of the 38 children with ventricular tachycardia. Effectiveness of therapy was assessed with the combined use of 24 hour Holter monitoring and graded treadmill exercise testing in 14 children, and with multiple 24 hour Holter monitoring alone in 14. In 4 (Patients 1, 3, 12 and 32) of the 14 children who underwent both exercise testing and Holter monitoring, the tachycardia appeared to be abolished on 24 hour Holter monitoring, but treadmill exercise still provoked the tachycardia.

The results of the last 24 hour Holter and last treadmill test (when available) in 28 children on antiarrhythmic therapy are summarized in Table IV.
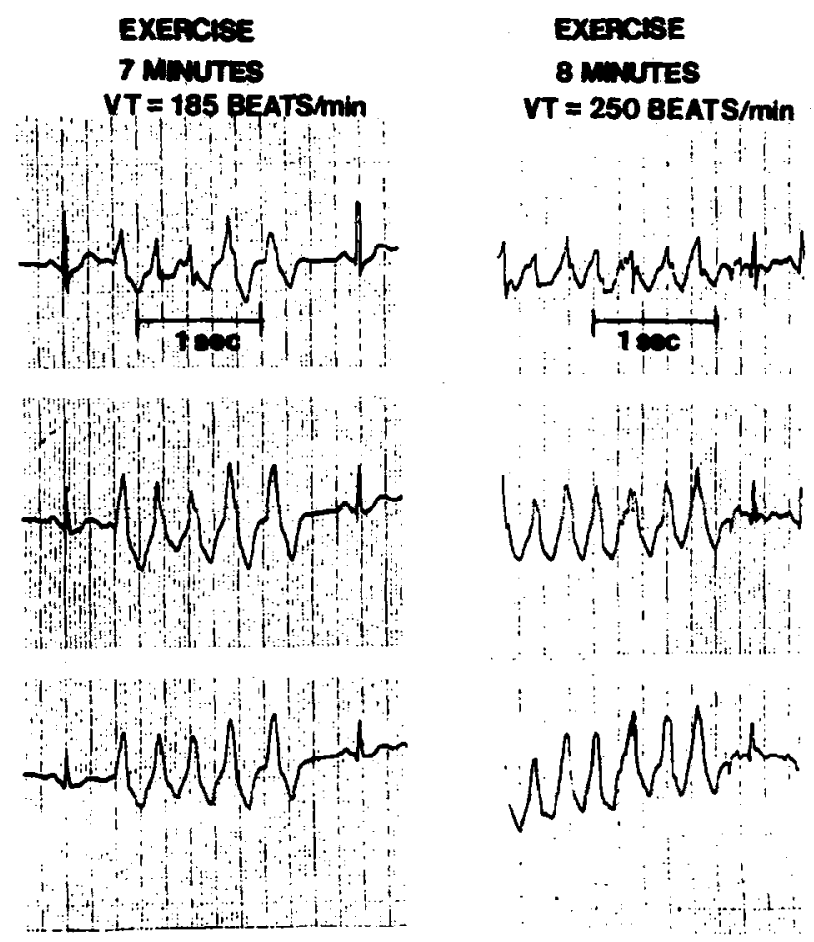
Therapy eliminated symptoms and abolished ventricular tachycardia in all 23 symptomatic patients, but failed to abolish tachycardia in 2 of 5 treated asymptomatic patients (Cases 7 and 24). Only a few complications of antiarrhythmic therapy were noted in the 28 children; quinidine caused fever and diarrhea in patient 18 and phenytoin caused gingival hypertrophy in $\mathrm{Pa}$ tients 9 and 12 .

Antiarrhythmic agents: A wide spectrum of antiarrhythmic agents have been used in our children with ventricular tachycardia. including propranolol, quinidine, phenytoin, digitalis and procainamide. Certain drugs were more effective in specific groups of children. Propranolol alone eliminated symptoms and ventricular tachycardia in three children with mitral valve prolapse. However, in Patients 1 and 3, propranolol abolished ventricular tachycardia on 24 hour Holter monitoring, but exercise, still provoked the tachycardia. Only after the addition of quinidine was ventricular tachycardia effectively controlled. In the three patients with a prolonged Q-T syndrome, the combination of propranolol and phenytoin effectively controlled symptoms and abolished ventricular tachycardia.

Phenytoin appeared to be the antiarrhythmic agent of choice in our patients after repair of tetralogy of Fallot. Phenytoin alone abolished ventricular tachycardia and symptoms in Patients 13 to 15 . In Patient 12, ventricular tachycardia was not completely eliminated by quinidine and digitalis, but was abolished with the addition of phenytoin.

\section{Discussion}

Prognosis: Limited information is available on the long-term follow-up and management of children and adolescents with ventricular tachycardia. It is clear from our study, as well as from previous reports, ${ }^{1-9}$ that ventricular tachycardia may occur in children with or without evidence of heart disease. In our patients, three factors appeared to be helpful in predicting the prognosis of children with ventricular tachycardia: (1) the presence of underlying cardiac disease, (2) the rate of tachycardia, and (3) the response of the child to graded treadmill exercise.

Role of underlying heart disease: Symptomatic ventricular tachycardia occurred more frequently in children with than in children without underlying heart disease. In addition, the children with heart disease not only had more symptoms, but also had more severe symptoms. Mitral valve prolapse, myocarditis and repaired tetralogy of Fallot were the conditions most frequently associated with ventricular tachycardia. Pedersen et al. ${ }^{2}$ also found that mitral valve prolapse was the most frequent underlying condition associated with ventricular tachycardia. Swartz et al. ${ }^{11}$ reported that ventricular tachycardia occurred in 37 of 589 adult patients with mitral valve prolapse (6.3 percent). Although the origin of arrhythmias in patients with mitral valve prolapse is unknown, Gooch et al. ${ }^{12}$ suggested that left ventricular asynergy may be partly responsible for the arrhythmias observed in patients with mitral valve prolapse. All five of our children with mitral valve pro-
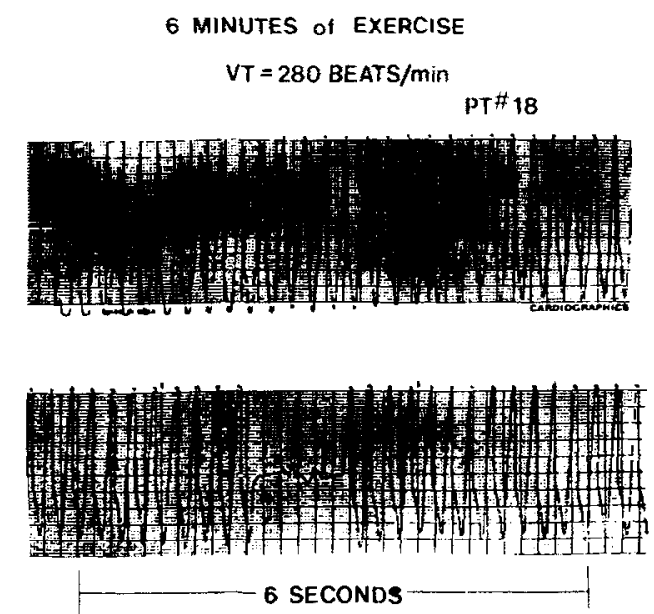

FIGURE 4. Patient 18 (aortic insufficiency). A continuous lead II thythm strip is displayed. Ventricular flutter at a rate of 280 beats/min developed after 6 minutes of treadmill exercise testing. During the tachycardia, the patient experienced hypotension, angina and chest pain. Cardioversion was required to terminate the ventricular tachycardia (VT).

lapse and ventricular tachycardia had left ventricular asynergy ("ballerina foot pattern,"13 anterior convex bulging during late systole and early diastole).

Role of rate of tachycardia: Our data also suggested that the rate of ventricular tachycardia affects the nature of the patient's symptoms. All of our symptomatic patients, with or without heart disease, had ventricular tachycardia at rates greater than 150 beats/min. Three patients (Cases 28, 31 and 32) had asymptomatic ventricular tachycardia for 5 to 8 years at a rate of greater than 150 beats/min before a syncopal episode developed. Others ${ }^{14-17}$ have also reported the benign nature of slow ventricular tachycardia and have chosen to call this condition accelerated ventricular rhythm rather than ventricular tachycardia. ${ }^{14-17}$ Pedersen et al. ${ }^{2}$ reported that the rate of ventricular tachycardia influences the nature of the patient's symptoms but believed that a slower rate did not necessarily assure a good prognosis since two of their three patients who died had ventricular tachycardia with a rate of 154 and 158 beats/min, respectively.

Prognostic value of exercise testing: Finally, we observed that the response of patients to graded stress exercise testing was useful in predicting the prognosis in children with ventricular tachycardia. In the symptomatic patient, exercise usually increased the degree of ventricular arrhythmia; in the asymptomatic patient, exercise abolished the arrhythmia or decreased its degree. Ryan et al. ${ }^{18}$ also demonstrated that exercise testing was useful in evaluating ventricular arrhythmia in adults with coronary artery disease. In contrast, Pedersen et al..$^{2}$ did not find the results of stress testing prognostically helpful in their patients with ventricular tachycardia, but did observe that exercise suppressed the ventricular tachycardia in patients with slow ventricular tachycardia (rates less than 150 beats $/ \mathrm{min}$ ). The poor prognostic value of exercise testing in the study of 
TABLE IV

Results of Antiarrhythmic Therapy in 28 Children With Ventricular Tachycardia

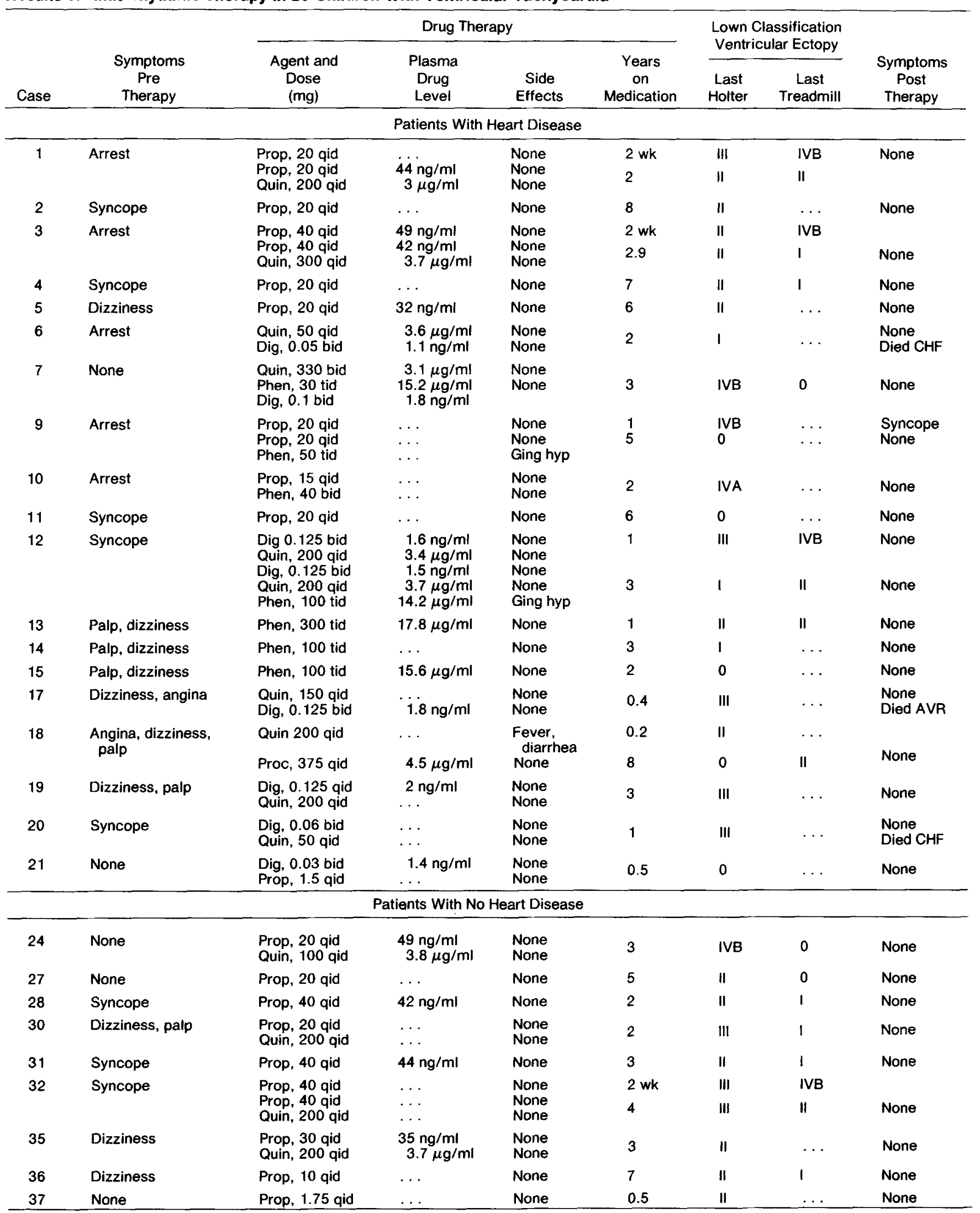

I = less than 1 premature ventricular complex/min; II = 1 premature ventricular complex/min; II = multifocal premature ventricular complexes; IVA = couplets; IVB = ventricular tachycardia; Ging hyp = gingival hypertrophy; other abbreviations as in Table I. 
Pedersen et al. ${ }^{2}$ may relate to both the small overall number of patients and the very small number of asymptomatic patients in their study.

Effect of antiarrhythmic therapy: The majority of our children, with or without heart disease, are on some form of antiarrhythmic therapy. In our symptomatic children, antiarrhythmic therapy was effective in abolishing ventricular tachycardia, reducing ventricular arrhythmia and eliminating symptoms. However, in the asymptomatic child, arrhythmia control appeared to be less effective. Although no double blind protocol was used to determine the best antiarrhythmic agent for treating children with ventricular tachycardia, certain drugs appear to be most effective in specific groups of children (propranolol in mitral valve prolapse, propranolol and phenytoin in prolonged Q-T syndrome and phenytoin in postoperative tetralogy of Fallot ${ }^{19}$ ). We also found that the combined use of both 24 hour Holter monitoring and repeated graded treadmill exercise testing was the best noninvasive means of eval- uating drug effectiveness. Ryan et al. ${ }^{18}$ also reported that 24 hour Holter monitoring and graded treadmill exercise testing were complementary methods that divulged different information regarding the electrophysiologic state of the myocardium. More recently, we have also used electrophysiologic studies to evaluate drug efficacy.

Clinical implications: Our data suggest that the presence of underlying cardiac disease, the rate of the ventricular tachycardia and the results of graded treadmill exercise testing are useful in predicting the prognosis of children with ventricular tachycardia. Although the long-term effects of chronic antiarrhythmic therapy in the growing child are not known, we currently recommend antiarrhythmic therapy for all symptomatic patients with ventricular tachycardia and for those asymptomatic patients with both ventricular tachycardia rates greater than 150 beats/min and a significant increase in ventricular arrhythmia with stress testing.

\section{References}

1. Gillette P. Ventricular dysrhythmias. In: Roberts ND, Gelband $H$, eds. Cardiac Arrhythmias in the Neonate, Infant and Child. New York: Appleton-Century-Crofts, 1977:195.

2. Pedersen DH, ZIpes DP, Foster PR, Troup PJ. Ventricular tachycardia and ventricular fibrillation in a young population. Circulation 1979;60:977-88.

3. Hernandez A, Straus A, Lerger RE, Goldring D. Idiopathic paroxysmal ventricular tachycardia in infants and children. J Pediatr 1975:86:182-8.

4. Herman RH, Scrupter LJ, Mattingly TW. Recurrent ventricular tachycardia as the chief manifestation of myocarditis of unknown etiology. Am Heart J 1959;57:829-48.

5. Radford DJ, Izukawa T, Rowe RD. Evaluation of children with ventricular arrhythmias. Arch Dis Child 1977;52:345-53.

6. Coumel P, Fidelle J, Lucet $V$, Attuel P, Bouviain Y. Catecholamine-induced severe ventricular arrhythmias with Adam-Stokes syndrome in children: report of four cases. Br Heart J 1978;40: 28-32.

7. Abildskov JA. The nervous system and cardiac arrhythmias. Circulation 1975;52:Suppl III:III-116-9

8. Adams CW. Functional paroxysmal ventricular tachycardia. Am J Cardiol 1962;9:215-22.

9. Videbaek J, Andersen ED, Jacobsen JR, Sandoe E, Wennevold A. Paroxysmal tachycardia in infancy and children-II. Paroxysmal ventricular tachycardia and fibrillation. Acta Paediatr Scand 1973:62:349-58.
10. Doan AE, Peterson DR, Blackmon JR, Bruce RA. Myocardial ischemia after maximal exercise in healthy men. Am Heart $\mathrm{J}$ 1965;69:11-21.

11. Swartz M, Teichholz L, Donoso E. Mitral valve prolapse: a revlew of associated arrhythmias. Am J Med 1977;62:377-89.

12. Gooch A, Vlcencia F, Maranhao V, Goldberg H. Arrhythmias and left ventricular asynergy in the prolapsing mitral leaflet syndrome. Am J Cardiol 1972;29:611-20.

13. Scampardonis G, Yang S, Maranhaw V, Goldberg H, Gooch A Left ventricular abnormalities in prolapsed mitral leaflet syndrome. Am J Cardiol 1973;48:287-97.

14. Gaum WE, Blancanicello T, Kaplan S. Accelerated ventricular rhythm in childhood. Am J Cardiol 1979;43:162-6.

15. Massumi RA, Ali N. Accelerated isorhythmic ventricular rhythms. Am J Cardiol 1970;26:170-85.

16. Zipes DP, Fisch CP. Accelerated ventricular rhythm. Arch Intern Med 1972;129:650-2.

17. Schamroth L. Idioventricular tachycardia. J Electrocardiol 1968;1:205-12.

18. Ryan M, Lown B, Horn H. Comparison of ventricular ectopic activity during 24 hour monitoring and exercise testing in patients with coronary heart diseases. N Engl J Med 1975;299:224-32.

19. Garson A, Kugler JD, Gillette PC, Simonelli A, McNamara DG Control of late postoperative ventricular arrhythmias with phenytoin in young patients. Am J Cardiol 1980;46:290-4. 